\title{
FLOTAÇÃO ANIÔNICA DE REJEITO DO MINÉRIO DE FERRO DE CAUÊ $\hat{A}^{*}$
}

\author{
Marisa Martins ${ }^{1}$ \\ Marisa Bezerra de Mello Monte 2 \\ Wagner Silva ${ }^{3}$ \\ Leandro Seixas Bicalho \\ Laurindo de Salles Leal Filho
}

\section{Resumo}

Este trabalho aborda o processamento de rejeito proveniente do circuito de flotação de minério de ferro da mina de Cauê. A amostra utilizada no presente estudo apresentou teores médios de $27 \%$ de $\mathrm{Fe}, 59 \%$ de $\mathrm{SiO}_{2}$ e $1,4 \%$ de $\mathrm{Al}_{2} \mathrm{O}_{3}$. A concentração de hematita contida neste rejeito foi avaliada, utilizando-se flotação aniônica em meio ácido e na presença do ânion $\mathrm{SiF}_{6}{ }^{2-}$, como depressor da ganga silicatada. De posse da caracterização granulométrica, química e mineralógica do rejeito, ensaios tecnológicos de flotação foram executados, objetivando a avaliação dos variados sistemas de reagentes. Diferentes dosagens dos depressores $\mathrm{H}_{2} \mathrm{SiF}_{6} \mathrm{e}$ $\mathrm{Na}_{2} \mathrm{Si}_{6}$ e ainda de três diferentes tipos de coletores aniônicos foram avaliados. Os melhores resultados foram alcançados pelos coletores do tipo ácido graxo e sulfonato de petróleo, os quais geraram concentrados contendo $66 \%$ de $\mathrm{Fe}$ e $4 \%$ de $\mathrm{SiO}_{2}$, e recuperações metalúrgicas de $\mathrm{Fe}$ de $59 \%$ e $71 \%$, respectivamente.

Palavras-chave: Minério de ferro; Flotação aniônica; Rejeito.

\section{ANIONIC FLOTATION OF IRON ORE TAILING FROM CAUÊ \\ Abstract}

This work addressed the processing of tailing from Cauê iron ore industrial circuit. The sample contained $27 \% \mathrm{Fe}, 59 \% \mathrm{SiO}_{2}$ and $1.4 \% \mathrm{Al}_{2} \mathrm{O}_{3}$. Value addition to this reject material has been investigated using anionic flotation in acidic medium and in the presence of $\mathrm{SiF}_{6}{ }^{2-}$, as depressant. Size analyses, chemical and mineralogical characterization and flotation tests were performed aiming to verifying the flotation response of the several reagent systems. Different dosages of depressants $\mathrm{H}_{2} \mathrm{SiF}_{6}$ and $\mathrm{Na}_{2} \mathrm{SiF}_{6}$ and anionic collectors were used. With optimum parameters (type and concentration of depressants and collectors), the grade of cleaner concentrate was $66 \% \mathrm{Fe}, 4 \% \mathrm{SiO}_{2}$ and iron recovery rate of $59 \%$ (fatty acid collector) and $71 \%$ (sulfonate collector). The promising results of the laboratory scale tests showed that a great amount of iron minerals can be reclaiming.

Keywords: Iron ore; Anionic flotation; Tailing.

1 Química, Doutora em Eng. Mineral, Pesquisadora, Instituto Tecnológico Vale - Mineração, Ouro Preto, Minas Gerais, Brasil.

2 Engenheira Química, Doutora em Eng. Metalúrgica e de Materiais, Pesquisadora Titular, Instituto Tecnológico Vale - Mineração, Ouro Preto, Minas Gerais, Brasil.

3 Químico, Mestre em Eng. Metalúrgica e de Materiais, Coordenador do Laboratório CADM-BH, Clariant OMS, Belo Horizonte, Minas Gerais, Brasil.

4 Engenheiro de Minas, Analista de Processos Mining, Clariant OMS, Belo Horizonte, Minas Gerais, Brasil.

5 Formação/graduação, Doutor em Eng. Mineral, Diretor Científico, Instituto Tecnológico Vale Mineração, Ouro Preto, Minas Gerais, Brasil. 


\section{INTRODUÇÃO}

O desafio de se manter o crescimento das atividades minerárias em sintonia com diretrizes de desenvolvimento sustentável tem motivado os estudos de recuperação de hematita presente nos rejeitos gerados no beneficiamento de minério de ferro. Este trabalho teve como objetivo avaliar a viabilidade técnica de concentrar a hematita contida em amostra de rejeito final do circuito de flotação de Cauê (Itabira/MG), através de flotação aniônica direta. Buscou-se obter um concentrado final de hematita apresentando teores de $\mathrm{SiO}_{2} \leq 4 \%$ e de $\mathrm{Fe} \geq 65 \%$, o qual pode ser utilizado para compor um blend com o produto sinter feed, para ser comercializado.

A concentração de hematita a partir dos rejeitos da flotação de minério de ferro pode ser executada através de flotação aniônica direta utilizando ácidos graxos, sulfonato de petróleo ou hidroxamato de alquila [3]. Para tais coletores, a flotação deve ser conduzida em pH abaixo do Ponto Isoelétrico (IEP) do mineral. O IEP da hematita ocorre na faixa de $5,0 \leq \mathrm{pH} \leq 8,5$, enquanto que o IEP da goethita ocorre numa faixa mais estreita de $\mathrm{pH}: 6,1 \leq \mathrm{pH} \leq 7,2$ [5]. Em ambos os casos, as variações verificadas no IEP dos minerais podem ser devidas a impurezas existentes em sua superfície, advindas de um condicionamento geológico diferenciado [1]. Os coletores aniônicos são oriundos de ácidos fracos (oleato e hidroxamato) ou fortes (sulfonato) e se dissociam segundo a Equação 1.

Onde: $\mathrm{X}^{-}=$Ânion coletor

$$
\mathrm{HX} \leftrightarrow \mathrm{H}^{+}+\mathrm{X}^{-}
$$

$\mathrm{HX}=$ Coletor na forma molecular.

Alquil sulfonatos são eletrólitos fortes $\left(\mathrm{pK}_{\mathrm{a}}=1,5\right)$ e, por isto, encontram-se predominantemente ionizados acima de $\mathrm{pH}=1,5$. A interação desses coletores com os óxidos de ferro é controlada por um mecanismo predominantemente eletrostático e, por isto, o pH de flotação é uma variável muito importante. Deste modo, infere-se que a faixa de $\mathrm{pH}$ adequada para se trabalhar com tais coletores é $1,5<\mathrm{pH}<\mathrm{IEP}$. Mesmo raciocínio pode ser usado para alquil sulfatos.

No que concerne à flotação direta de óxidos de ferro com ácidos graxos, existe consenso de que a máxima resposta à flotação ocorre em $\mathrm{pH} 8$, no qual a superfície destes minerais é composta predominantemente pela espécie $\mathrm{FeOH}[6,8]$. A máxima resposta à flotação com ácidos graxos ocorre, em geral, em pH próximo ao IEP do mineral [4]. Embora um máximo de flotabilidade da hematita ocorra em $\mathrm{pH} \mathrm{8,} \mathrm{a}$ quantidade de oleato adsorvida na interface hematita/solução neste $\mathrm{pH}$ não é máxima. De fato, a quantidade de oleato adsorvida é estritamente decrescente com o aumento do pH da solução [4]. Segundo Quast (1999) [7], em valores de pH mais alcalinos ocorre a competição entre íons oleato e hidroxila pelos sítios ativos presentes na superfície da hematita. Em um trabalho recente, observa-se que não existe concordância de opinião entre pesquisadores no que concerne ao mecanismo de adsorção de oleato em hematita [3].

Vieira (1994) [9] estudou a viabilidade técnica de concentração de Itabirito através de flotação aniônica direta, em escala de bancada, com oleato de sódio, obtendo-se um concentrado contendo $65,5 \%$ de $\mathrm{Fe}$ e $4,7 \%$ de $\mathrm{SiO}_{2}$ para uma recuperação metalúrgica de $\mathrm{Fe}$ de $78 \%$, em $\mathrm{pH}=7$ e na ausência de depressor para a ganga silicatada.

Lopes (2009) [2] avaliou os coletores oleato de sódio, AERO 6493 (hidroxamato) e AERO 825 (sulfonato) na flotação aniônica de minério de ferro da Serra da 
Serpentina, utilizando silicato de sódio como depressor de silicatos. Com o oleato de sódio, em $\mathrm{pH}=7$, foi obtido concentrado contendo $58 \%$ de $\mathrm{Fe}, 14 \%$ de $\mathrm{SiO}_{2} \mathrm{e}$ recuperação metalúrgica de $\mathrm{Fe}$ de $88 \%$. Com o sulfonato, em $\mathrm{pH}=4$, foi obtido concentrado contendo $58 \%$ de $\mathrm{Fe}, 13 \%$ de $\mathrm{SiO}_{2}$ e recuperação metalúrgica de $\mathrm{Fe}$ de $90 \%$. Os melhores resultados foram alcançados com o hidroxamato em $\mathrm{pH}=7$, obtendo-se concentrado com $62 \%$ de $\mathrm{Fe}, 10 \%$ de $\mathrm{SiO}_{2}$ e recuperação metalúrgica de Fe de $78 \%$.

\section{MATERIAIS E MÉTODOS}

A amostra de rejeito final do circuito de flotação foi coletada na usina de Cauê (Itabira) e, após desaguamento, foi homogeneizada a úmido em pilha cônica e em pilha alongada, de onde foi retirada uma alíquota para análise química, outra para caracterização por MLA e o restante quarteado em padrões de alimentação da flotação de $600 \mathrm{~g}$, base úmida. O teor de umidade foi determinado em triplicata, resultando em um valor médio de $13,5 \%$. Deste modo, cada padrão possui massa de $519 \mathrm{~g}$, base seca.

A composição química do rejeito foi determinada por fluorescência de raios- $X$, enquanto a composição mineralógica, grau de liberação e associação mineral foram obtidos por MEV/MLA.

Avaliação do efeito da presença de amina residual no rejeito foi realizada por intermédio de um ensaio de flotação sem adição de reagentes, sendo observada a formação de espuma, porém sem a ocorrência de flotação da amostra (recuperação mássica igual à zero). Além disso, a determinação quantitativa de amina, após ensaio de escrubagem da amostra, revelou concentração inferior a 3ppm de tal coletor, não sendo suficiente para influenciar os futuros ensaios de flotação aniônica com esta amostra.

Os ensaios de flotação foram conduzidos utilizando célula de bancada, operando a 1200 rotações por minuto. A rota investigada foi a de flotação aniônica direta com uma etapa rougher e três etapas cleaner. Deste modo, preparava-se uma polpa com $50 \%$ de sólidos e, nos ensaios realizados em meio ácido, o pH era ajustado pela adição de $\mathrm{H}_{2} \mathrm{SiF}_{6}$ ou $\mathrm{H}_{2} \mathrm{SO}_{4}+\mathrm{Na}_{2} \mathrm{SiF}_{6}$. Em seguida, adicionava-se o coletor, na dosagem e pH desejados, condicionando-se por 2 minutos. Executava-se a flotação rougher, cujo tempo variou de 1,5 a 3 minutos, de acordo com o coletor utilizado. 0 produto flutuado alimentava a etapa cleaner seguinte, até o terceiro cleaner. Os produtos gerados em cada ensaio de flotação eram secados, pesados e alíquotas eram amostradas e enviadas para análise química. A relação dos reagentes utilizados nos ensaios de flotação é apresentada na Tabela 1.

Tabela 1: Relação dos reagentes utilizados na flotação.

\begin{tabular}{|c|c|c|}
\hline Reagente & Função & Modo de adição \\
\hline Ácido Graxo - 070 & Coletor aniônico & Solução saponificada ${ }^{*}$ 5\% \\
\hline Ester Fosfórico - 071 & Coletor aniônico & Solução $5 \%$ \\
\hline Sulfonato - 080 & Coletor aniônico & Solução $5 \%$ \\
\hline $\mathrm{H}_{2} \mathrm{SO}_{4}$ & Regulador de pH & Solução $10 \%$ \\
\hline $\mathrm{H}_{2} \mathrm{SiF}_{6}$ & Regulador de pH e Depressor & Solução $10 \%$ \\
\hline $\mathrm{Na}_{2} \mathrm{SiF}_{6}$ & Depressor & Solução $10 \%$ \\
\hline
\end{tabular}

$\left(^{*}\right)$ Saponificação: $5 \mathrm{~g}$ do produto para $7,5 \mathrm{~mL}$ de $\mathrm{NaOH}(10 \%)$. 


\section{RESULTADOS E DISCUSSÃO}

\subsection{Caracterização da Amostra de Rejeito Final}

A composição química por faixa granulométrica do rejeito é apresentada na Tabela 2 , onde se observa que $\circ \mathrm{Fe}(27 \%)$ e $\mathrm{SiO}_{2}(59 \%)$ são os principais elementos presentes na amostra. O Fe se distribui preferencialmente nas frações mais finas, menores que $0,105 \mathrm{~mm}$, enquanto a sílica $\left(\mathrm{SiO}_{2}\right)$ apresenta comportamento oposto, tendendo a se concentrar nas frações acima de $0,105 \mathrm{~mm}$.

Tabela 2 - Composição química da amostra de rejeito.

\begin{tabular}{|c|c|c|c|c|c|c|c|c|c|c|c|}
\hline \multirow{2}{*}{$\begin{array}{c}\text { Fração } \\
\text { (mm) }\end{array}$} & \multicolumn{2}{|c|}{$\%$ Massa } & \multicolumn{5}{|c|}{ Teores ( $\%$ em massa) } & \multicolumn{4}{|c|}{ Distribuição no ensaio (\%) } \\
\hline & ret. & acum. & $\mathrm{Fe}$ & $\mathrm{SiO}_{2}$ & $\mathrm{Al}_{2} \mathrm{O}_{3}$ & $\mathbf{P}$ & PF & $\mathrm{Fe}$ & $\mathrm{SiO}_{2}$ & $\mathrm{Al}_{2} \mathrm{O}_{3}$ & $\mathrm{P}$ \\
\hline$+0,21$ & 14,5 & 14,5 & 1,88 & 94,6 & 1,17 & 0,01 & 0,62 & 1,0 & 23,6 & 13,2 & 12,3 \\
\hline$-0,21+0,15$ & 11,0 & 25,5 & 3,69 & 92,2 & 0,91 & 0,01 & 0,86 & 1,5 & 17,4 & 7,7 & 9,1 \\
\hline$-0,15+0,10$ & 18,8 & 44,3 & 10,6 & 82,5 & 0,73 & 0,01 & 0,40 & 7,4 & 26,6 & 10,7 & 13,7 \\
\hline$-0,10+0,074$ & 16,7 & 61,0 & 35,9 & 45,5 & 0,99 & 0,01 & 0,71 & 22,4 & 13,1 & 12,9 & 14,1 \\
\hline$-0,074+0,044$ & 16,3 & 77,3 & 32,1 & 51,1 & 1,09 & 0,01 & 0,54 & 19,6 & 14,4 & 13,8 & 14,7 \\
\hline$-0,044+0,037$ & 6,5 & 83,8 & 57,0 & 14,7 & 1,25 & 0,02 & $\cdots$ & 13,7 & 1,6 & 6,3 & 6,8 \\
\hline$-0,037$ & 16,2 & 100,0 & 56,9 & 11,6 & 2,81 & 0,03 & 1,51 & 34,4 & 3,2 & 35,4 & 29,3 \\
\hline Total calculado & 100,0 & & 26,8 & 58,1 & 1,29 & 0,02 & $\cdots$ & 100,0 & 100,0 & 100,0 & 100,0 \\
\hline Total dosado & & & 27,0 & 58,6 & 1,38 & 0,02 & 0,49 & & & & \\
\hline
\end{tabular}

Os resultados obtidos por MEV/MLA para a composição mineralógica indicam o quartzo $(67 \%)$ como maior constituinte e a hematita (31\%) como o mineral portador de ferro na amostra, além da presença de micas $(1,3 \%)$ e outros silicatos $(1,1 \%)$.

A distribuição das associações da hematita com os demais minerais constituintes da amostra (\%massa), por faixa de tamanho, é apresentada na Figura 1, onde se observa que a liberação global da hematita é de $90 \%$. Entretanto, partículas de hematita acima de $0,105 \mathrm{~mm}$ possuem liberação deficiente, apresentando valores de apenas $12 \%$ acima de $0,210 \mathrm{~mm}$ e de $40 \%$ na fração $-0,210+0,150 \mathrm{~mm}$, aumentando para $76 \%$ em $-0,150+0,105 \mathrm{~mm}$. Na forma mista, a hematita ocorre principalmente em associações binárias com quartzo. 


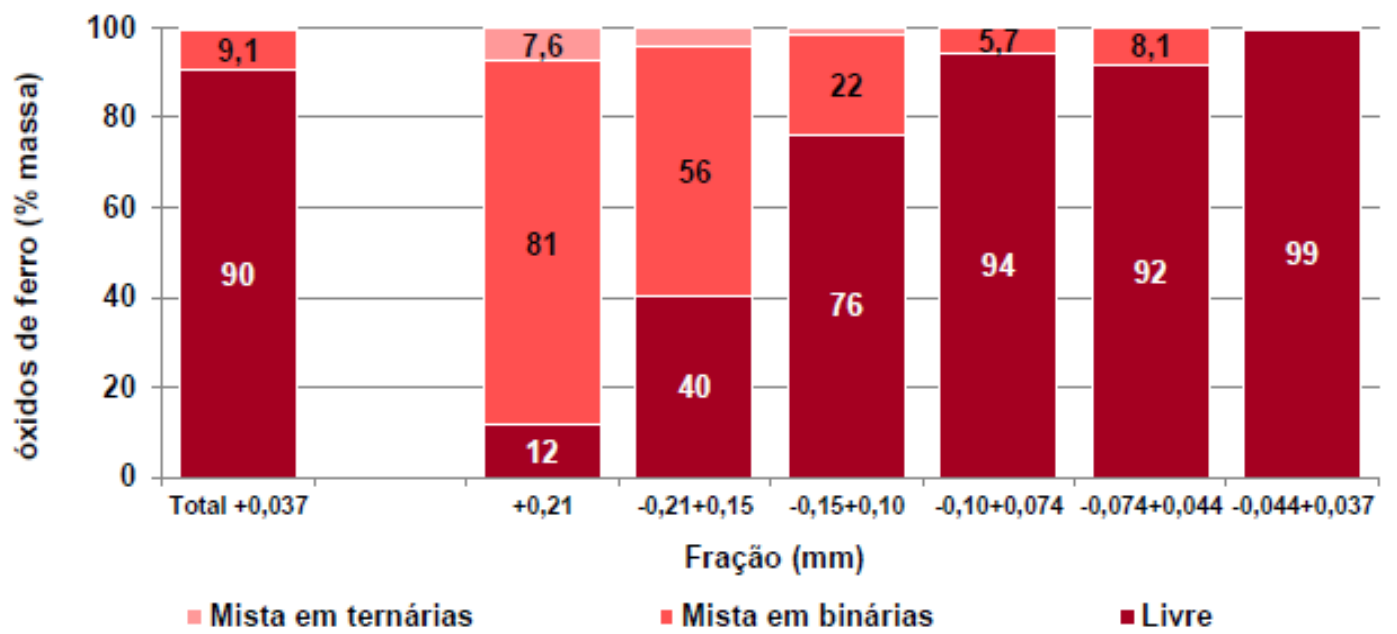

Figura 1 - Distribuição das associações da hematita por fração granulométrica.

\subsection{Efeito do Tipo de Coletor na Flotação Aniônica do Rejeito}

Estes ensaios visaram avaliar o desempenho de três coletores aniônicos fabricados pela Clariant, com diferentes funcionalidades: ácido graxo, éster fosfórico e sulfonato. A dosagem do coletor foi mantida em $200 \mathrm{~g} / \mathrm{t}$, variando-se $\mathrm{o} \mathrm{pH}$ entre natural $(7<\mathrm{pH}<8)$ e faixa ácida $(4<\mathrm{pH}<5)$. Os resultados obtidos na etapa rougher são apresentados na Figura 2, onde se verifica que os ensaios realizados em $\mathrm{pH} \sim 5$ exibiram maiores teores de ferro e menores teores de $\mathrm{SiO}_{2}$, tanto para o ácido graxo quanto para o éster fosfórico. A presença do depressor para silicatos $\mathrm{SiF}_{6}{ }^{2-}$ no ácido utilizado $\left(\mathrm{H}_{2} \mathrm{SiF}_{6}\right)$ para ajustar o $\mathrm{pH}$ possivelmente colaborou para estes resultados. O sulfonato foi avaliado apenas na faixa ácida e os baixos valores de recuperação mássica e de $\mathrm{Fe}$ obtidos (5,8\% e 9,6\%, respectivamente) indicam a necessidade de se avaliar dosagens mais altas para este coletor.

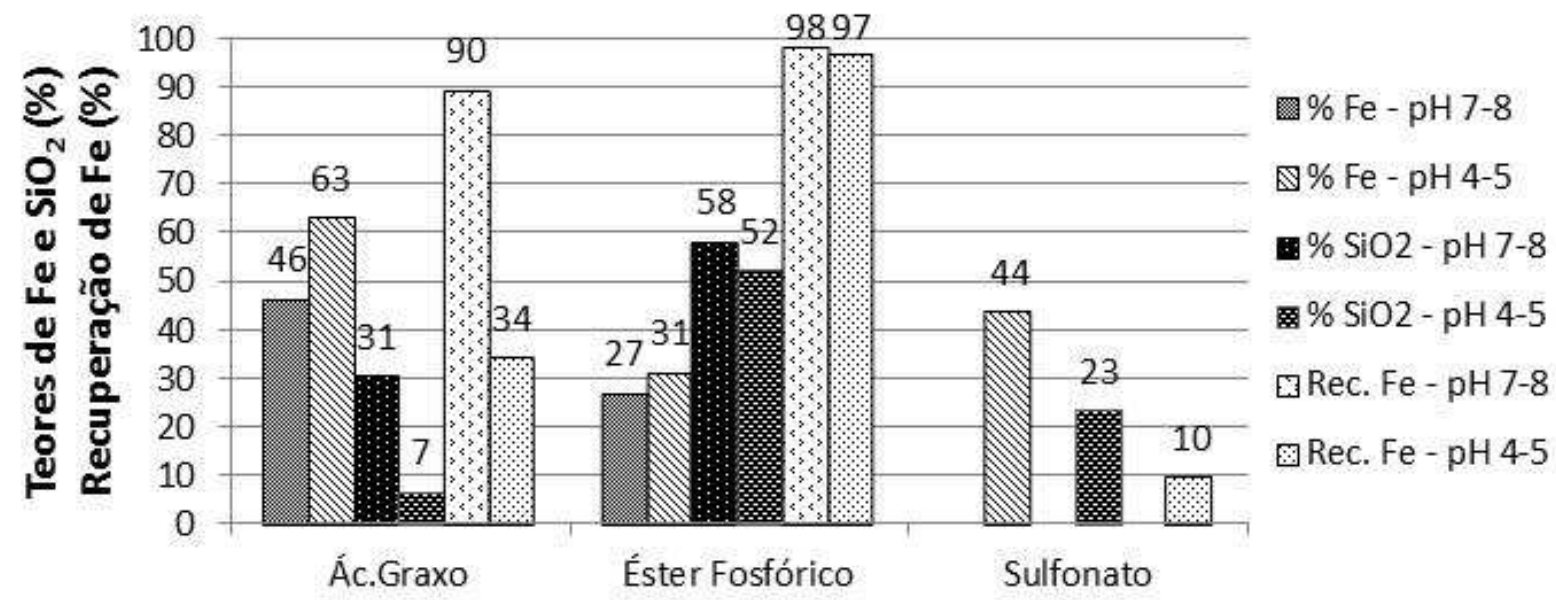

Coletores Aniônicos

Figura 2: Desempenho dos coletores aniônicos em diferentes valores de $\mathrm{pH}$.

Dentre os reagentes avaliados, o ácido graxo apresentou maior seletividade e o menor teor de $\mathrm{SiO}_{2}$ no concentrado obtido em $\mathrm{pH} 5$. Entretanto, foi obtida baixa recuperação de ferro, provavelmente pelo fato deste reagente não se encontrar totalmente dissociado nesta faixa de $\mathrm{pH}$. Tal resultado indica a necessidade de se avaliar maiores dosagens deste coletor. O éster fosfórico não foi tão seletivo quanto 
o ácido graxo, apresentando altos conteúdos de $\mathrm{SiO}_{2}$, tanto em meio ácido quanto natural.

\subsection{Flotação Aniônica com o Coletor Ácido Graxo}

Ensaios foram realizados para avaliar o efeito depressor do $\mathrm{SiF}_{6}{ }^{2-}$ sobre a ganga silicatada, buscando-se melhorar a seletividade da flotação de hematita com ácido graxo. Deste modo, variou-se a dosagem do depressor, mantendo-se a dosagem do coletor em $600 \mathrm{~g} / \mathrm{t}$ e ajustando $0 \mathrm{pH}=5 \mathrm{com}$ ácido sulfúrico. Os resultados obtidos para o concentrado da terceira etapa cleaner são apresentados na Figura 3. O aumento da concentração do ânion depressor $\mathrm{SiF}_{6}{ }^{2-}$ acarretou no aumento do teor de $\mathrm{Fe}$ e da seletividade (IS). Os resultados mostrados na figura 3 indicam que 0 aumento da seletividade se deve ao papel desempenhado pelo depressor $\mathrm{SiF}_{6}{ }^{2-}$, pois todos os ensaios foram realizados em $\mathrm{pH}=5$.

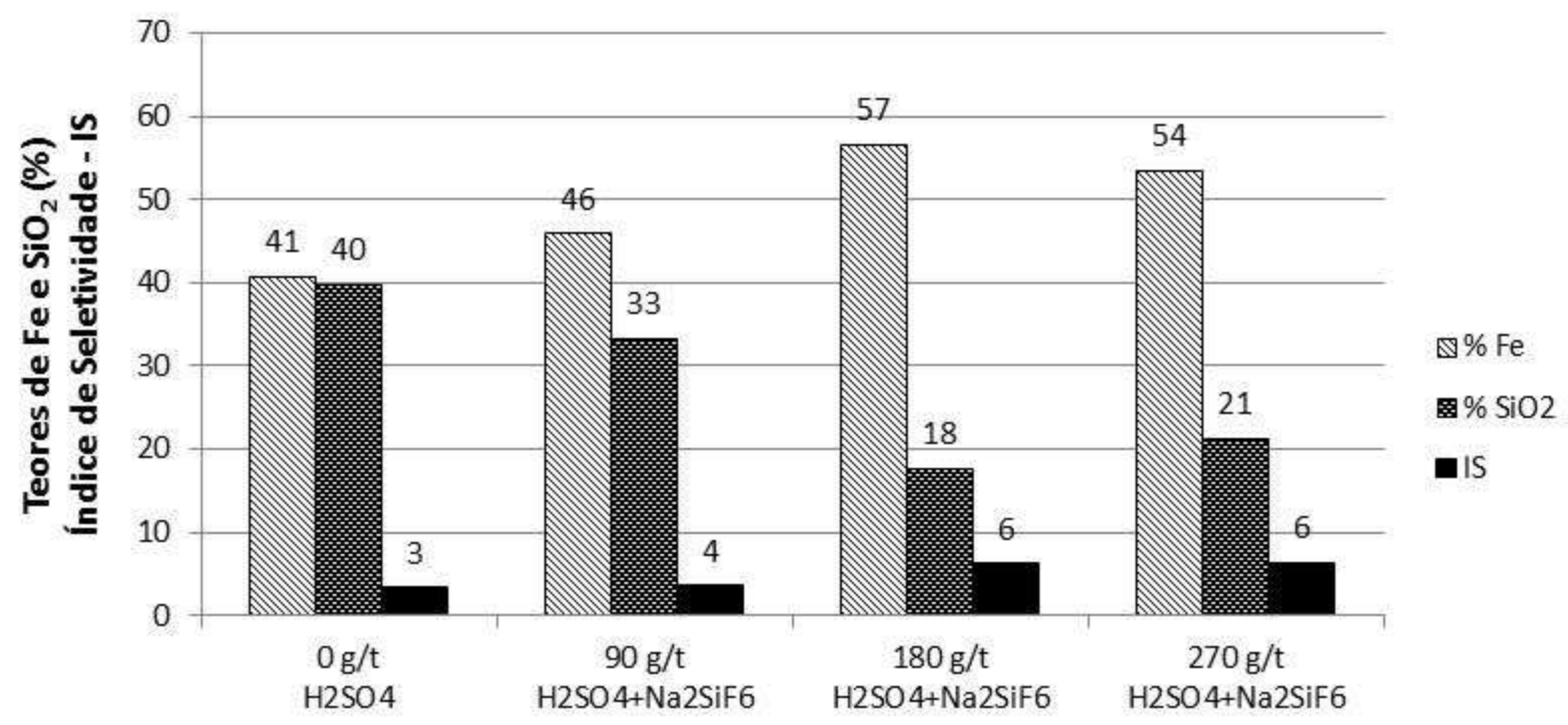

Dosagem do Depressor

Figura 3: Efeito da dosagem do depressor fluorsilicato no desempenho da flotação de hematita com ácido graxo. (dosagem do coletor $=600 \mathrm{~g} / \mathrm{t}, \mathrm{pH}=5$ ).

Avaliou-se ainda a forma de adição do depressor fluorsilicato, como ácido $\left(\mathrm{H}_{2} \mathrm{SiF}_{6}\right)$ e/ou como sal $\left(\mathrm{Na}_{2} \mathrm{SiF}_{6}\right)$. Os resultados obtidos para o concentrado cleaner-3 são apresentados na Figura 4. Para a dosagem de depressor de $90 \mathrm{~g} / \mathrm{t}$, a adição na forma de ácido fluorsilícico apresentou melhores resultados que o sal fluorsilicato de sódio. Do mesmo modo, para a dosagem de $270 \mathrm{~g} / \mathrm{t}$ de depressor, quando parte deste foi adicionada na forma de ácido, a seletividade (IS) e o teor de ferro aumentaram e o teor de sílica diminuiu consideravelmente, obtendo-se um concentrado que atende a meta de teor de $\mathrm{Fe}(66 \% \geq 65 \%)$ e com teor de sílica muito próximo ao desejado $(5 \% \cong 4 \%)$. 


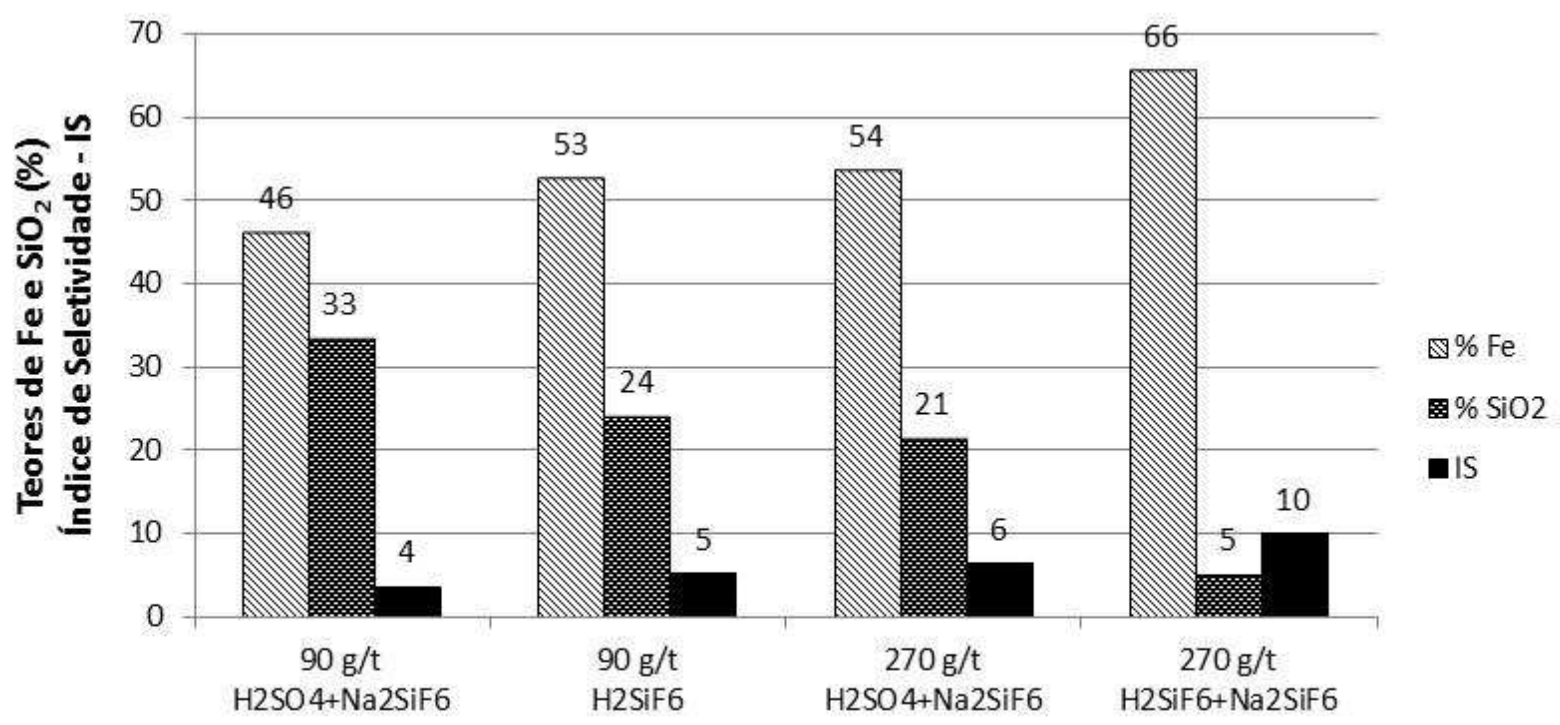

Forma de Adição de Depressor

Figura 4: Efeito da forma de adição do depressor fluorsilicato no desempenho da flotação de hematita com ácido graxo. (dosagem de ácido graxo $=600 \mathrm{~g} / \mathrm{t}, \mathrm{pH}=5$ ).

A Figura 5 apresenta o efeito da dosagem do ácido graxo na recuperação metalúrgica do $\mathrm{Fe}$ e ainda nos teores de $\mathrm{Fe}$ e $\mathrm{SiO}_{2}$ do concentrado cleaner-3. Conforme pode ser observado, a aplicação de $500 \mathrm{~g} / \mathrm{t}$ do ácido graxo, em $\mathrm{pH}=5$, mostrou ser possível obter um concentrado que atenda as especificações químicas de produto que pode ser utilizado para compor um blend com sinter feed $\left(\mathrm{SiO}_{2} \leq 4 \%\right.$ e de $\mathrm{Fe} \geq 65 \%$ ). Com o aumento da dosagem do coletor para $600 \mathrm{~g} / \mathrm{t}$, observa-se um aumento na recuperação metalúrgica de ferro, porém o teor de Fe no concentrado final aumenta para de $4 \%$ para $5 \%$.

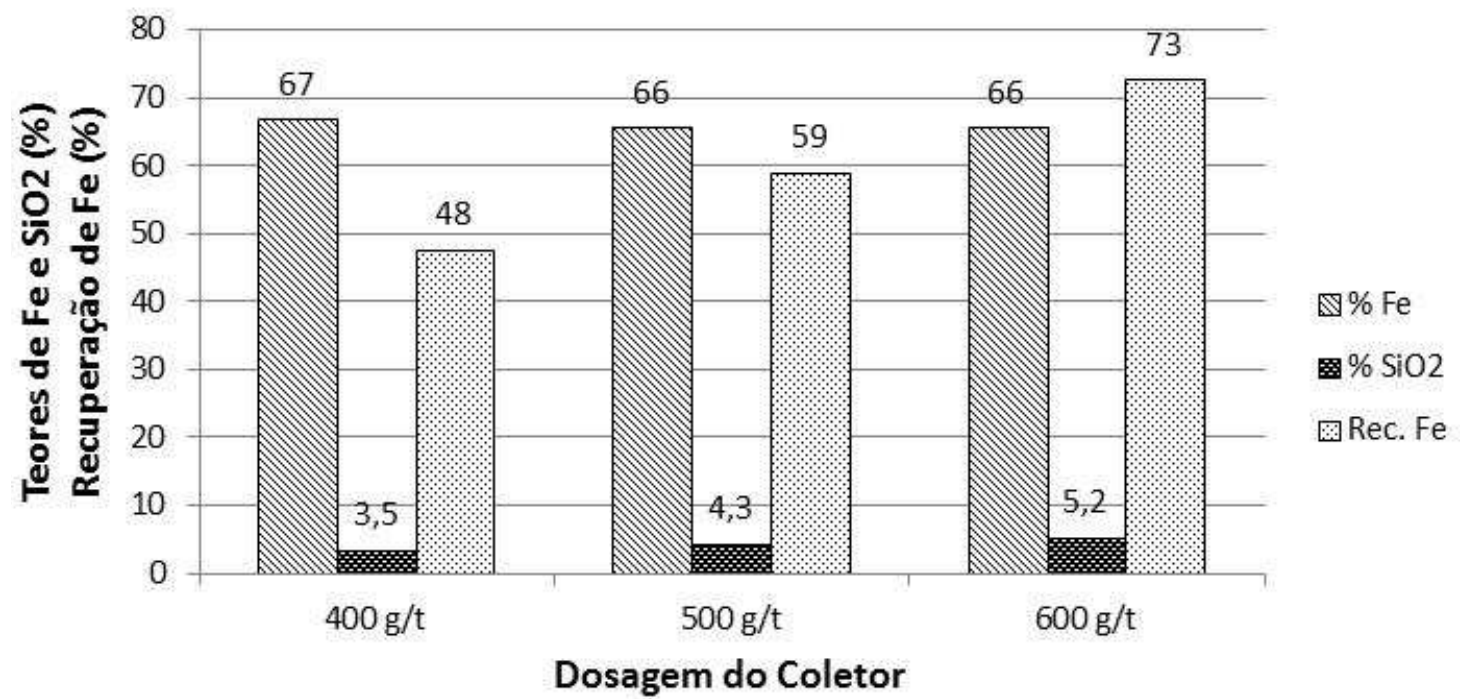

Figura 5: Efeito da dosagem do coletor ácido graxo no desempenho da flotação de hematita. (dosagem do depressor $=270 \mathrm{~g} / \mathrm{t}, \mathrm{pH}=5$ ).

\subsection{Flotação Aniônica com o Coletor Sulfonato}

Indicada a necessidade de se avaliar maiores dosagens para o reagente sulfonato, ensaios foram realizados em $\mathrm{pH}$ ácido, mantendo-se a dosagem do depressor em 
$90 \mathrm{~g} / \mathrm{t}$ e aumentando-se a dosagem do coletor de $200 \mathrm{~g} / \mathrm{t}$ até $1000 \mathrm{~g} / \mathrm{t}$. Os resultados são apresentados na Figura 6, onde se verifica que os valores de seletividade e de recuperação de $\mathrm{Fe}$ no concentrado rougher aumentaram com o acréscimo da dosagem do coletor.

Ensaio de flotação em que se adotaram três etapas de limpeza cleaner foi realizado para a dosagem de $1000 \mathrm{~g} / \mathrm{t}$ de sulfonato e $90 \mathrm{~g} / \mathrm{t}$ de depressor, visando obter concentrado final mais rico em ferro e com menor teor de $\mathrm{SiO}_{2}$. Os resultados são apresentados na figura 7 , onde se verifica que a adoção das etapas cleaner foi capaz de gerar concentrado final que atende à meta de teor de $\mathrm{Fe}(\% \mathrm{Fe} \geq 65 \%)$ e de sílica $\left(\mathrm{SiO}_{2} \leq 4 \%\right)$. Entretanto, observa-se também que o aumento da dosagem do depressor e sua forma de adição não teve efeito significativo na qualidade do concentrado final.

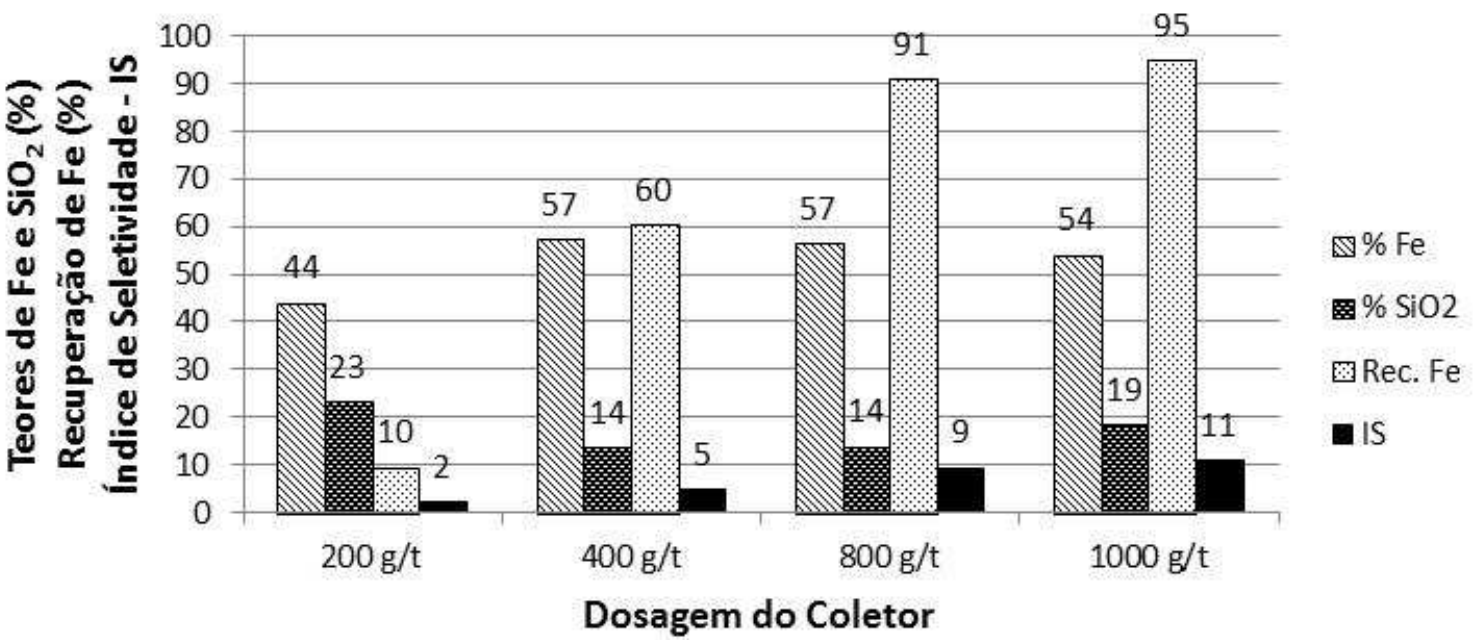

Figura 6: Efeito da dosagem do coletor sulfonato no desempenho da flotação de hematita. (dosagem do depressor $=90 \mathrm{~g} / \mathrm{t}, \mathrm{pH}=4$ ).

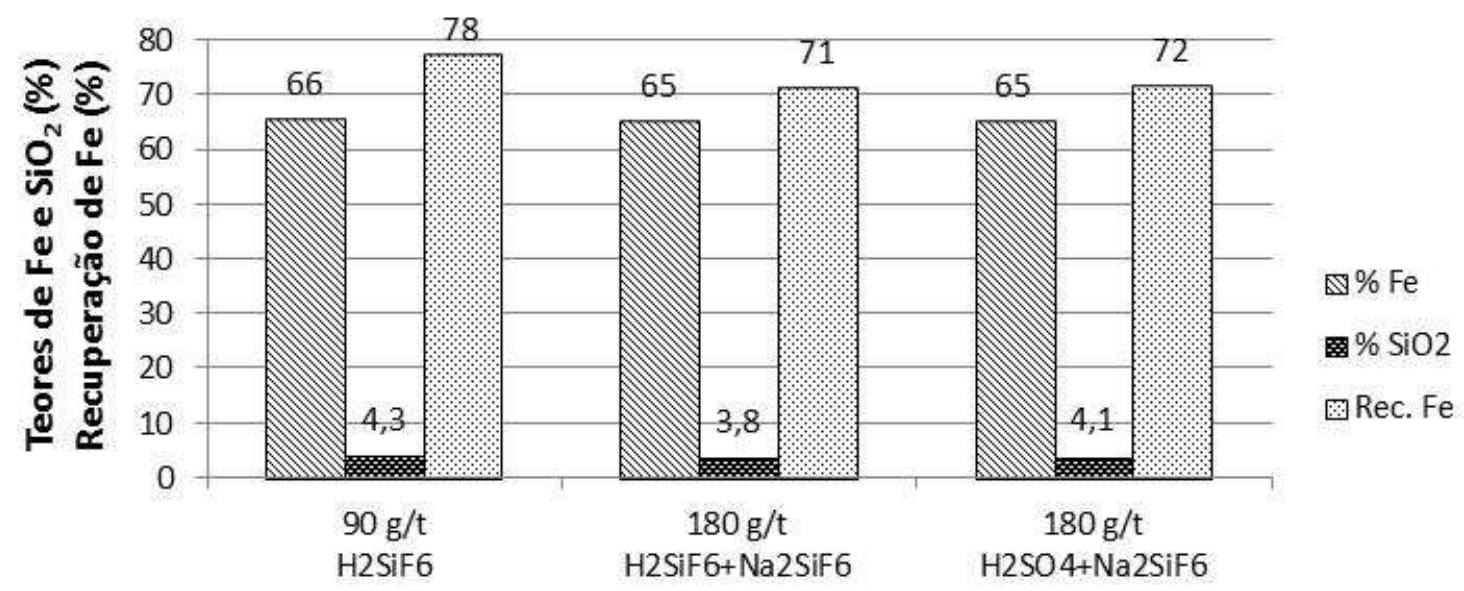

Dosagem e Forma de Adição do Depressor

Figura 7: Efeito da dosagem do depressor fluorsilicato e de sua forma de adição no desempenho da flotação de hematita. (dosagem de sulfonato $=1000 \mathrm{~g} / \mathrm{t}, \mathrm{pH}=4$ ).

\section{CONCLUSÃO}

A realização de flotação aniônica direta da hematita com uma etapa rougher e três etapas cleaner, em pH 5 e na presença do ânion depressor $\mathrm{SiF}_{6}{ }^{2-}$, resulta em maior 
seletividade na separação entre hematita e a ganga silicatada. Os melhores resultados foram alcançados com os coletores do tipo ácido graxo e sulfonato de petróleo.

Nas condições de $500 \mathrm{~g} / \mathrm{t}$ de ácido graxo, $\mathrm{pH}=5$ e $270 \mathrm{~g} / \mathrm{t}$ de depressor $\mathrm{SiF}_{6}{ }^{2-}$, obtevese um concentrado de hematita que atende a especificação química de teores de $\mathrm{Fe}$ $(66 \%>65 \%)$ e de $\mathrm{SiO}_{2}(4,2 \% \cong 4,0 \%)$ para compor blend com sinter feed, e com recuperação metalúrgica de $\mathrm{Fe}$ de $59 \%$. Aumentando-se a dosagem de ácido graxo para $600 \mathrm{~g} / \mathrm{t}$, a recuperação de ferro atinge $73 \%$, porém o teor de $\mathrm{SiO}_{2}$ aumenta para $5 \%$ e deixa de atender ao valor desejado de $4 \%$. A seletividade da flotação aumentou quando parte do depressor é adicionado na forma do ácido fluorsilícico, ao invés de adicioná-lo totalmente na forma do sal fluorsilicato de sódio.

Com o coletor sulfonato, na dosagem de $1000 \mathrm{~g} / \mathrm{t}, \mathrm{pH}=4$ e dosagem de depressor de $180 \mathrm{~g} / \mathrm{t}$, adicionado na forma de $\mathrm{H}_{2} \mathrm{SiF}_{6}(90 \mathrm{~g} / \mathrm{t})+\mathrm{Na}_{2} \mathrm{SiF}_{6}(90 \mathrm{~g} / \mathrm{t})$, obteve-se concentrado de hematita que atende a especificação química de teores de $\mathrm{Fe}(66 \%$ $>65 \%)$ e de $\mathrm{SiO}_{2}(3,8 \%<4,0 \%)$ para compor blend com sinter feed, e com recuperação metalúrgica de $\mathrm{Fe}$ de $71 \%$. O aumento da dosagem do depressor e sua forma de adição não teve efeito significativo na qualidade do concentrado final.

\section{REFERÊNCIAS}

1 Kulkarni, R.D.; Somasundaran, P. Mineralogical heterogeneity of ore particles and its effects on their interfacial characteristics. Powder Technology. 1976; 14: 279-85.

2 Lopes, G.M. Flotação direta de minério de ferro. Ouro Preto. Dissertação [Mestrado em Engenharia de Minas] - Universidade Federal de Ouro Preto; 2009.

3 Miller, J.D.; Khalek, A.; Basilio, C.; El-Shall, H.; Fa, K.; Forssberg, K.S.E.; Fuerstenau, M.C.; Mathur, S.; Nalaskowski, J.; Rao, K.H.; Somasundaran, P. Wang, X.; Zhang, P. Flotation chemistry and technology of nonsulfide minerals. In: Fuerstenau,M.C,; Jameson, G.; Yoon, R.H. Froth flotation - A century of innovation. Littleton: SME; 2007. p.465-553.

4 Morgan, L.J. Oleate adsorption on hematite: problems and methods. Int. Journal of Mineral Processing. 1986; 18: 139-152.

5 Parks, G.A. The isoelectric points of solid oxides, solid hydroxides and aqueous hydroxo complex systems. Chem. Rev. 1965; 65: 177-183.

6 Peck, A.S.; Raby, L.W.; Wadsworth, M.E. An infrared study of the flotation of hematite with oleic acid and sodium oleate. Trans. AIME. 1966; 235: 301-307.

7 Quast, K.B. Flotation of hematite using oleate as collectors. The AusIMM Proceedings. 1999; 1: 7-13.

8 Somasundaran, P., and R. B. Grieves. Advances in interfacial phenomena of particulate/solution/gas systems: applications to flotation research. New York: American Institute of Chemical Engineers; 1975.

9 Vieira, A.M. Estudo da viabilidade técnica da concentração de um minério de ferro de baixo teor. Belo Horizonte. Dissertação [Mestrado em Engenharia de Minas] Universidade Federal de Minas Gerais; 1994. 